\title{
O ouro sob as Luzes: a 'arte' de minerar no discurso do naturalista João da Silva Feijó (1760-1824)*
}

\author{
Gold under the Lights: the "art" of mining in the discourse \\ of naturalist João da Silva Feijó (1760-1824)
}

Clarete Paranhos da Silva

Doutoranda no Instituto de Geociências da Unicamp Caixa Postal 6152

13083-970 Campinas — SP Brasil clarete@ige.unicamp.br

\section{Maria Margaret Lopes}

Professora do Instituto de Geociências da Unicamp Caixa Postal 6152

13083-970 Campinas — SP Brasil mmlopes@ige.unicamp.br
SILVA, C. P. da, LOPES, M. M.: 'O ouro sob as Luzes: a "arte" de minerar no discurso do naturalista João da Silva Feijó (1760-1824)'.

História, Ciências, Saúde-Manguinhos, vol. 11(3): 731-50, set.-dez. 2004.

João da Silva Feijó foi um naturalista luso-brasileiro comissionado pela Coroa portuguesa, na transição entre os séculos XVIII e XIX, para fazer investigações em história natural. Foi enviado para as ilhas de Cabo Verde (1783-1797) e para a capitania do Ceará, no Brasil (1799). Ao regressar de Cabo Verde e antes de ser enviado ao Brasil, Feijó escreveu em Lisboa um Discurso sobre as minas de ouro do Brasil, em que apresenta suas opiniões sobre tal matéria. Neste artigo tecemos alguns comentários preliminares sobre as idéias contidas no Discurso, que aqui é transcrito tendo em vista seu caráter inédito e sua importância como parte de um conjunto maior de textos do período relativos à crise da mineração no Brasil.

PALAVRAS-CHAVE: história do Brasil, geociências, mineração, mineralogia, história natural.

SILVA, C. P. da, LOPES, M. M.: 'Gold under the Lights: the "art" of mining in the discourse of naturalist João da Silva Feijó (1760-1824)'.

História, Ciências, Saúde-Manguinhos, vol. 11(3): 731-50, Sept.-Dec. 2004.

João da Silva Feijó was a Luso-Brazilian naturalist commissioned by the Portuguese Crown to conduct natural history research between the eighteenth and nineteenth centuries. He was sent to the Cape Verde islands (1783-97) and then to the captaincy of Ceará, in Brazil (1799). Upon returning from Cape Verde to Lisbon, prior to bis Brazilian mission, Feijó laid out his opinions on Brazil's gold mines in a manuscript entitled Discourse. The present article offers some preliminary comments on the ideas found in Discourse. Given its importance as part of a larger set of period texts on the mining crisis in Brazil, this manuscriptnever before published - is also transcribed herein.

KEYWORDS: bistory of Brazil, geosciences, mining, mineralogy, natural history. 


\section{Introdução}

I números autores têm destacado as 'viagens filosóficas' coordenadas pela Academia Real das Ciências de Lisboa em conjunto com a Universidade de Coimbra e com o Museu da Ajuda e especificamente por Domingos Vandelli ${ }^{1}$ — uma das realizações científicas mais significativas do século XVIII português.

De acordo com a obra clássica de Simon (1983) sobre as expedições científicas portuguesas no ultramar, Vandelli teria planejado, ao longo de alguns anos, enviar diversos de seus alunos a uma grande expedição ao Brasil. Mas em 1782 tais planos foram radicalmente alterados, com as designações de Manuel Galvão da Silva como secretário de governo para Moçambique e de Joaquim José da Silva para Angola, razão por que Alexandre Rodrigues Ferreira teria sido o único do grupo inicial a seguir para o Brasil. O mesmo autor — aparentemente sem maiores informações — afirma que o naturalista João da Silva Feijó partira para uma relativa obscuridade em Cabo Verde, em uma variada carreira de químico, oficial militar e professor, e eventualmente teria retornado ao Rio de Janeiro. Simon não tece considerações sobre os cerca de 15 anos em que Feijó esteve no Ceará.

O levantamento documental e bibliográfico que realizamos sobre o naturalista João da Silva Feijó (1760-1824) é exemplar no que demonstra o quanto ainda está por ser feito para se obter uma compreensão mais abrangente sobre as trajetórias e produções de naturalistas que tiveram papéis proeminentes na cultura ilustrada luso-brasileira, no final dos Setecentos.

\section{O naturalista João da Silva Feijó}

João da Silva Feijó nasceu no Rio de Janeiro no ano de 1760 e morreu em 1824, na mesma capitania. Durante muitos anos trabalhou como naturalista a serviço da Coroa portuguesa, prestando seus serviços no Reino, em Cabo Verde e na capitania do Ceará, no Brasil. Alguns autores, como Simon (op. cit.), Carreira (1986), Guedes (1997) e Guedes e Arruda (2000), afirmam que sua formação acadêmica deu-se na Universidade de Coimbra, já reformada por Pombal. Ali teria freqüentado o curso de história natural ministrado por Domingos Vandelli e recebido o título de bacharel em matemática. Porém o nome de Feijó não consta na lista dos Estudantes brasileiros na Universidade de Coimbra (17721872), que se encontra na Biblioteca Nacional. Em seu Dicionário bibliográfico, Sacramento Blake (1898) afirma que Feijó formouse em matemáticas, mas não indica o local de formação do naturalista. Outros autores, como Silva Nobre (1978), sugerem que Feijó teria cursado a Academia Militar de Lisboa. Entretanto a 
leitura de suas Memórias não deixa dúvida de que ele incluiu-se entre os discípulos de Vandelli.

Além de seu trabalho no Brasil, Feijó, que foi sóciocorrespondente da Academia Real das Ciências de Lisboa, empreendeu uma viagem filosófica pelas ilhas de Cabo Verde, onde teria permanecido de 1783 a 1797. Antes dessa viagem esteve, juntamente com o naturalista Alexandre Rodrigues Ferreira (17561815), nas minas de carvão de Buarco, com o intuito de conhecer melhor as possibilidades locais. Estas e outras viagens feitas por naturalistas, tanto no Reino como nas colônias, inserem-se em um contexto no qual medidas de recuperação levadas a cabo pelo Estado português eram fortemente informadas pela ciência (Silva, 1999). Durante o tempo em que permaneceu em Cabo Verde, Feijó elaborou diversos artigos que foram posteriormente publicados. ${ }^{2}$

Feijó chegou ao Ceará em outubro de 1799, com o objetivo de cumprir aquilo que lhe fora designado em provisão de 25 de fevereiro de 1799 assinada por dona Maria I: estudar todas as potencialidades naturais da região.

Dona Maria, por graça de Deus Rainha de Portugal e dos Algarves ... faço saber aos que esta minha carta patente virem que eu hei por bem fazer mercê a João da Silva Feijó da patente de Sargento Mor de Milícias da Capitania do Ceará para onde deve partir, incumbido de vários objetos de História Natural, continuando a vencer naquela Capitania o mesmo ordenado de quatrocentos mil réis que aqui cobrava, e com o posto haverá o soldo que lhe tocar, pago na forma de minhas reais ordens... ${ }^{3}$

Ocupando o cargo de sargento-mor das milícias, Feijó cumpre seu ofício de naturalista na região mapeando, descrevendo e explorando objetos de história natural. Deste trabalho emergem algumas cartas topográficas e um grande número de memórias que seriam posteriormente publicadas, como se constata pela relação dos trabalhos que localizamos até o presente momento. Entre eles, encontram-se em análise por nós:

- Preâmbulo ao ensaio filosófico e político sobre a Capitania do Ceará para servir para a sua bistória geral, Rio de Janeiro, Imprensa Régia, 1810;

- Memória econômica sobre a raça do gado lanígero da Capitania do Ceará, com os meios de organizar os seus rebanhos por princípios rurais, aperfeiçoar a espécie atual das suas ovelhas e conduzir-se ao tratamento delas e das suas lãs em utilidade geral do comércio do Brasil e prosperidade da mesma capitania; escrita e oferecida ao príncipe regente, Rio de Janeiro, 1811, publicada no Auxiliar da Indústria Nacional em 1842 e na edição facsimilar de separatas de artigos da Revista do Instituto do Ceará, 
tomo 3, Fortaleza, Biblioteca Básica Cearense/Fundação Waldemar Alcântara, 1997, pp. 368-97;

- Memória sobre a Capitania do Ceará, 1814, publicada no Patriota, tomo 3, n. 1, pp. 46-62 e na edição fac-similar de separatas de artigos da Revista do Instituto de Ceará, tomo 3, Fortaleza, Biblioteca Básica Cearense/Fundação Waldemar Alcântara, 1997, pp. 4-27;

- Memória sobre as minas de ferro do Cangati do Choró na Capitania do Ceará, escrita em 1814, Biblioteca Nacional (BN), Obras raras, 39,5,9;

- Memória sobre as antigas lavras de ouro da Mangabeira da Capitania do Ceará (1814?), publicada na edição fac-similar de separatas de artigos da Revista do Instituto do Ceará, tomo 3, Fortaleza, Biblioteca Básica Cearense/Fundação Waldemar Alcântara, 1997, pp. 367-70;

- Carta topográfica do Ceará à mina Salpetra, descoberta no sítio da Tatujuba na distância de 55 léguas da villa da Fortaleza, 1800, autógrafo na BN, Cartografia, ARC III - 4,6,13;

- Carta topográfica da Capitania do Ceará para servir à sua história geral, 1809, autógrafo no Arquivo Militar;

- Planta demonstrativa da Capitania do Ceará para servir de plano à sua carta topográfica, delineada pelo sargento mor naturalista, etc., 1810, cópia no Arquivo Militar;

- 'Coleção descritiva das plantas da Capitania do Ceará, 1818', em Estudos sobre a coleção descritiva das plantas do Ceará (com o original inédito do naturalista Feijó), Fortaleza, Gráfica Editorial Cearense, 1984 (coleção Estudos Cearenses). ${ }^{4}$

\section{O Discurso político sobre as minas de ouro do Brasil, 1797 - sua inserção no pensamento do período}

Do conjunto de publicações e correspondências do naturalista Feijó localizadas em diversas instituições nacionais e portuguesas, comentaremos neste artigo o seu Discurso politico sobre as minas de ouro do Brasil 5 , escrito em 1797 e que, de acordo com o estágio presente de nossos levantamentos, parece ter permanecido em manuscrito. A importância de sua divulgação deve-se ao fato de se tratar de mais uma obra inserida em um vasto acervo - que vem se ampliando a cada nova pesquisa - de memórias, artigos e discursos elaborados naqueles anos em torno da recuperação do setor de produção mineral no Brasil, nomeadamente a de ouro. ${ }^{6}$ Dentre esses escritos destacamos, a título de exemplos, o Discurso sobre o estado atual das minas do Brasil, do bispo José Joaquim da Cunha de Azeredo Coutinho e publicado em 1804 pela Imprensa Régia, em Lisboa, e o Discurso sobre a verdadeira 
influência das minas dos metais preciosos na indústria das nações que as possuem, e especialmente da portuguesa, escrito pelo ministro de dona Maria I, dom Rodrigo de Sousa Coutinho, e publicado pela Academia Real das Ciências de Lisboa, tomo I das Memórias econômicas (1789-1815). Do mesmo período final do século XVIII e começo do XIX — também são as inúmeras memórias sobre o tema, de naturalistas como José Bonifácio de Andrada e Silva (1763-1833) e José Vieira Couto (1752-1827) além de Feijó e muitos outros.

No âmbito desse debate, o texto de Feijó se destaca por se alinhar aos defensores da recuperação — por métodos racionais das atividades de mineração, como d. Rodrigo, José Bonifácio e Vieira Couto. Foi elaborado no período em que o naturalista, tendo retornado de sua viagem a Cabo Verde — provavelmente em $1797^{8}$ - , permaneceu em Lisboa, de onde partiria para o Ceará em 1799. Considerando as análises de Simon (op. cit.) e Brigola (op. cit.), levantamos a hipótese de que a redação desse discurso se inseriu no processo de capacitação e treinamento do naturalista realizado no complexo museológico da Ajuda, ainda pouco explorado pela historiografia. Ao mesmo tempo, Feijó - que tivera sua carreira interrompida em Cabo Verde - estaria evidenciando, com esse texto, conhecimento acerca das discussões sobre o tema e, portanto, plenas condições para a continuidade de seu trabalho como naturalista, o que poderia ter contribuído para que ele obtivesse a patente de sargento-mor de Milícias da capitania do Ceará, incumbido de vários objetos de história natural.

O Discurso politico sobre as minas de ouro do Brasil é dividido em três capítulos com pequenos parágrafos (14 ao todo), além de uma parte introdutória em que Feijó adianta sua opinião sobre as causas da crise no setor minerador do Brasil, as quais receberão tratamento mais detalhado em cada um dos capítulos que compõem o texto.

A seguir destacaremos trechos do Discurso que nos parecem relevantes para uma compreensão mais abrangente das idéias de Feijó, no que diz respeito à questão da mineração no Brasil. Para tal, acompanharemos a própria estrutura do manuscrito.

Já na introdução Feijó afirma ser a mineração, depois da agricultura, a arte mais interessante para a vida do homem, devido à utilidade das diversas produções que "a natureza cria e esconde nas entranhas da terra". O naturalista escreve que "poucos entre nós estão persuadidos da necessidade de certos e importantes conhecimentos", os quais seriam, a seu ver, fundamentais para a mineração. As causas da crise no setor mineral do Brasil estariam ligadas ao desconhecimento sobre mineralogia, geometria subterrânea e docimástica, que forneceriam os "princípios 
fundamentais" para a "arte das minas". A abundância e a facilidade de extração de ouro no Brasil haviam desfavorecido uma séria reflexão sobre o assunto, e a diminuição da produção que ora se observava seria motivo suficiente para "sérias contemplações políticas na indagação de suas causas". Nesse projeto o Estado assumiria papel primordial. Desde que se constituíssem em objetos da "ciência econômica" dos Estados, esses "entes naturais" poderiam ser mais bem aproveitados e se tornariam mais interessantes. Aqui Feijó tem diante de si os exemplos de regiões européias como França, Suécia e Alemanha. Por todas as suas vantagens, quais sejam, o aumento das rendas e dos fundos públicos, da moeda circulante, da manutenção e ampliação do trabalho nacional, a arte das minas tinha "ocupado as mais sérias atenções de sábios políticos e de prudentes Príncipes da Europa, em cujo domínio se extraem metais, particularmente o ouro, ou prata".

Além dessa causa mais geral, a "falta dos verdadeiros conhecimentos da arte de trabalhar as minas", Feijó enumera mais três fatores críticos: o desperdício e a adulteração do ouro, pela mistura com outro metal de propriedades semelhantes - que para o naturalista é conseqüência da primeira causa —; o uso do ouro em pó como moeda; e, por fim, os problemas de administração e fiscalização.

No capítulo 1, 'Que a diminuição atual do produto das minas provém da falta dos conhecimentos da Arte das Minas', Feijó compara a mineração no Brasil à época dos "primeiros descobrimentos das minas do ouro" com a que se faz ao tempo em que escreve o Discurso. A princípio o ouro aparecia à flor da terra e era extraído sem muito trabalho. Já na conjuntura contemporânea a seu texto, Feijó aponta as enormes dificuldades para a extração do metal. Esgotado o ouro de aluvião ou de superfície, acha-se "entranhado pelo centro das montanhas", ou talvez em "diferentes estados de mineralização ou combinação", não sendo reconhecido pelos mineiros, que desconhecem "todos os princípios fundamentais da arte de trabalhar as minas". Consonante com o espírito do século das Luzes, Feijó expressa sua confiança na instrução dos mineiros como uma das mais importantes atitudes a serem tomadas para a superação da crise pela qual passa o setor. O Brasil se ressentia da falta de professores de "Minas Metalúrgicas e de Docimástica", daí a ignorância com relação aos "princípios fundamentais" da arte mineira. A constatação leva-o a concluir que a causa primeira da queda da produção "é sem dúvida, a falta dos precisos conhecimentos por seus operários e diretores".

O capítulo 2, 'Que a mesma diminuição provém também do uso da circulação do ouro em pó', é bastante conciso. O objetivo é mostrar que uma situação detectada — a circulação de ouro 
em pó - deve ser modificada a fim de se aproveitar ao máximo o potencial econômico do metal. A circulação de ouro em pó acarreta a perda de quantias nada desprezíveis e facilita a "falsificação de mil maneiras praticada pela cobiça", o que, conseqüentemente, atuam contra o aumento da riqueza nacional. Segundo Feijó, "esta perda resulta um necessário desfalque nos quintos reais e de certa quantidade do trabalho que foi empregado na sua extração".

No capítulo 3, 'Da necessidade de regular os trabalhos das minas do ouro desde a sua extração até a redução em moeda', inspirando-se novamente em regiões de larga tradição em mineração como França, Suécia e Alemanha, Feijó sugere o que para ele é a maneira mais racional de controlar a atividade: uma regulação "debaixo de vistas mais ativas e inteligentes", para seu melhor aproveitamento e para evitar as já mencionadas perdas. Nota-se que Feijó defende a presença firme do Estado e de uma legislação que permita racionalizar a produção mineral. Somente a superfície da terra admite propriedade, seus subterrâneos são privativos do soberano, sendo este portanto o "supremo legislador" desse importante objeto que é a mineração. Citando os regulamentos da França, Suécia e Alemanha, o naturalista afirma ser necessário tomar os mesmos cuidados com as minas do Brasil. Não somente aponta problemas na administração do setor - cujas intendências, embora nas mãos de sábios homens e respeitáveis administradores "mais tendem a formalidades judiciais, que a dirigir, examinar, reparar e ensinar os meios de semelhantes trabalhos para serem verdadeiramente interessantes ao Estado" - , como esclarece sobre os meios mais eficazes adotados por aqueles Estados, em especial o francês, para tirar o máximo proveito de suas minas metálicas, entre eles o estabelecimento de aulas públicas, em que se repassavam conhecimentos da arte de trabalhar as minas, e a criação de "conselhos superiores de política das minas" para cuidar dessa importante parte dos negócios públicos. Feijó sugere que, em relação ao ensino dos conhecimentos sobre essa área, também a França deveria ser tomada como exemplo. À exemplo daquela nação, o ensino deveria compreender lições de mineralogia, química, docimástica, física, geometria subterrânea e hidráulica. Também seria importante instruir sobre o melhor modo de escavar e fazer galerias das minas e sobre construção de máquinas e fornos necessários aos trabalhos na mineração. A França inspira mais uma vez Feijó em suas sugestões ligadas a uma administração mais "profissional" das regiões mineiras. As intendências deveriam ser formadas por certo número de inspetores, "sujeitos de conhecidas luzes daquele negócio", que constituiriam "um corpo regular debaixo da previdência do seu respectivo intendente". 
O intendente mais os inspetores formariam um conselho responsável por discutir, julgar e deliberar sobre todos os assuntos relativos às minas "para de tudo ser informado exatamente o soberano".

Na opinião de Feijó, havia que se ter muito cuidado e atenção nas concessões de datas para a mineração. Era preciso evitar que, "por falta dos precisos conhecimentos", as minas fossem abandonadas assim que apresentassem as primeiras dificuldades, o que não aconteceria se as datas fossem cedidas apenas a "quem mostrasse ter qualidades para empreenderem tais trabalhos, e debaixo das restritas condições estipuladas, e fielmente guardadas pelos Conselhos das Intendências Reais".

Ainda para evitar os prejuízos causados pelo uso do ouro em pó no comércio, seria necessário estabelecer uma moeda efetiva e uma casa da moeda, com a "absoluta proibição do ouro em pó". Na concepção de Feijó, as providências por ele sugeridas "serviriam sem dúvida para estabelecer a boa ordem e economia nos trabalhos de nossas minas, e o devido arranjamento naquela parte das finanças".

\section{Considerações finais}

Conforme apontamos anteriormente, as questões discutidas por Feijó também eram objeto de inúmeras análises e preocupações do período. Entre estas questões destacam-se a utilização racional dos recursos econômicos, apoiada em sólidos princípios científicos, e o papel do Estado na condução de políticas 'racionais' que regulem a produção mineira. Da mesma forma que em outros textos da época, o Discurso caracteriza-se por uma forte retórica das Luzes, pela crítica ao desconhecimento dos 'princípios fundamentais' às práticas mineiras e por uma preocupação com a instrução e o treinamento dos mineiros. Como uma arte, a mineração deveria ser conduzida por "sujeitos de conhecidas luzes" que fossem capazes de colocar em prática seus conhecimentos para a melhor utilização dos recursos da natureza. Nesse sentido, o Discurso aponta alguns dos aspectos mais importantes que irão acompanhar as propostas de criação de escolas de mineração no país até o século XIX.

Em nossa opinião, a leitura, a divulgação e os comentários preliminares sobre esse documento - como também de toda a obra de cunho mineralógico de Feijó no Ceará — ajudam a demonstrar que as iniciativas relacionadas ao inventário dos recursos naturais de regiões da América portuguesa, especificamente com relação aos produtos do reino mineral, não se reduziram apenas às regiões de tradição mineira como Minas Gerais, Mato Grosso e Goiás (Pinheiro, Lopes, 2000). Tal constatação sugere a necessidade de estudos comparativos entre essas regiões tradicionalmente mineiras e outras — como por exemplo, o Ceará. 


\section{Discurso pollitico sobre as Minas do Ouro do Brasil por d. \&. Foijo, 1797}

\section{Untrodusäo}

Jodos saben que depois da Agricultura, não hà arte mais interessante à vida do homem

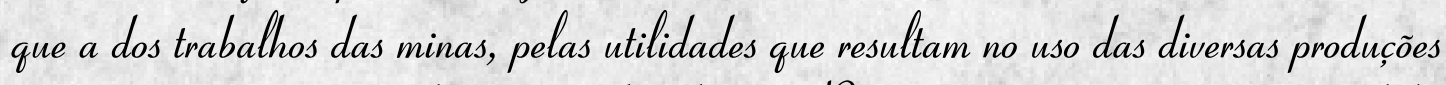

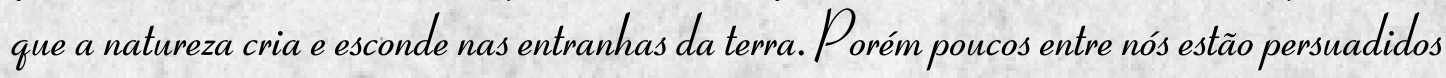
da necessidade de certos e importantes conhecimentos que como inseparaiveris constituem os seus principipos fundamentais, tais säo os da Mineralogia, os da Goometria Subterrañea, e os da Docimástica, sem o que jamais se pode dar, com vantagem, un só passo nos trabahlhos das minas.

Cm toda a parte do munalo polido tem sido osta verlade interiamente conhecida, de modo que

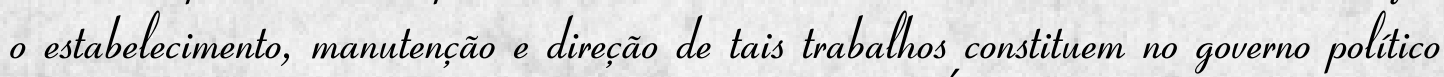

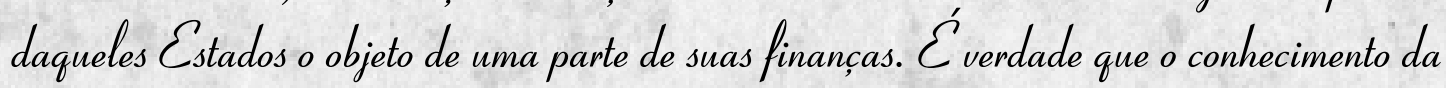
utitidadade destes entes naturais ao ¿stado, os meios peloss quais se podem fazer interessantes,

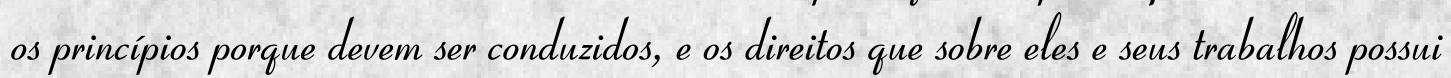
- Soberano, devem fazer uma parte de tão importante ciência econômica.

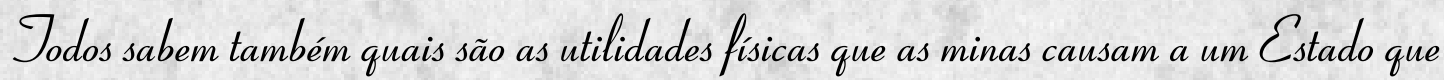

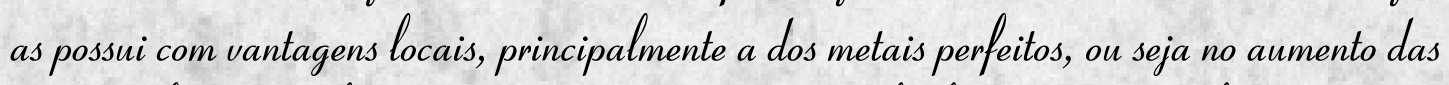

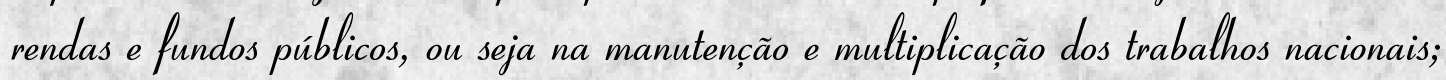

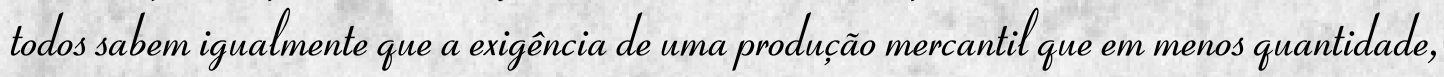

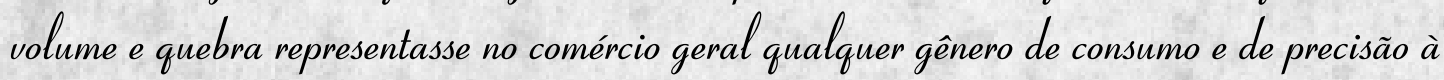
vida do homem social, fora esschlha do ourro e da prata para esse fim, por serem os metais os

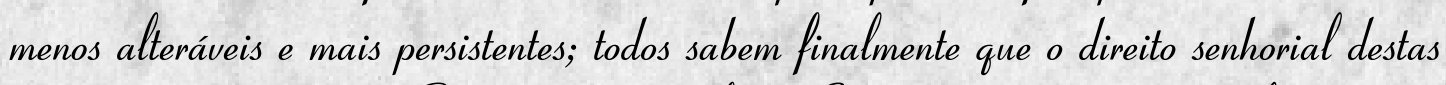
producoées so pertence ao Soberanono como chefe do Estado, que buscando com elas todas as vantagens do bem pubblico, deve fazé-has extrair com o maior proveito possivel, para fazer 
circular entre seus vassalos do modo o mais vantajoso aos seus interesses. Conseqüentemente a este Supremo Senhor pertence o mandar aproveitar as que possui nos seus domínios, dirigir o mais econômico possível os seus trabalhos, e fazer cunhar a precisa moeda debaixo da estabelecida fé de seu valor intrínseco. Estas [ilegível] tem por isso ocupado as mais sérias atenções de sábios políticos e de prudentes Príncipes da Curopa, em cujos domínios se extraem metais, particularmente o ouro, ou prata.

¿havendo entre nós chegado a perfeição todas as artes secundárias, é para admirar que possuindo nós as mais ricas e preciosas minas, tenha sido a verdadeira arte de as trabalhar totalmente desprezada, ou para melhor dizer, desconhecida. A abundância e fácil extração de ouro que tem produzido as minas do Brasil desde o seu descobrimento fez que até hoje não houvesse sobre os seus trabalhos uma séria reflexão. Porém, a grande diferença do produto atual que se deixa visivelmente perceber na diminuição dos rendimentos reais daquela repartição, e na decadência daqueles estabelecimentos, dá suficientemente matéria a sérias contemplações politicas na indagação de suas causas se não soubéssemos que a falta de arte, e a do regulamento preciso são as que tendem à sua total ruína. Csuposto que a análise desta matéria demande um talento superior e o mais iluminado em negócio de tanta consideração, contudo ainda que em min faltem tão importantes qualidades, o zelo compatriótico me conduz a mostrar neste pequeno discurso o mais sumário possível, que a diminuição do produto atual do ouro nas minas provém $1^{\circ}$ da falta dos verdadeiros conhecimentos da arte de trabalhar as minas; $2^{o}$ que esta falta de arte conduz ali não só a um irreparável desperdício de certa quantidade de ouro, mas ainda a poder ocasionar inopinadamente uma involuntária adulteração deste metal pela combinação com outro de semelhantes propriedades, vindo desta sorte alguma porção de nosso ouro a não ser verdadeiramente puro, depois das fundições e ensaios como se presume; $3^{\circ}$ que esta diminuição e prejuízo também provém do uso da comutação mercantil em ouro em pó; $4^{\circ}$ finalmente que os trabalhos das minas do Brasil desde a escavação do ouro até a sua redução em moeda necessitam ser conduzidos debaixo de vistas mais circunspectas, e ativas, o que tudo vai a fazer o objeto dos três seguintes capítulos. 


\section{Cap. $1^{\circ}$}

\section{Que a diminuigão atual do produto das minas provém da falta dos conhecimentos da Arte das Minas}

\section{\& 1}

Jodos sabem que nos primeiros descobrimentos das minas do ouro do Brasil este precioso metal aparecia quase a flor da terra, e muitas vezes em massas bem aunltadas, e que com pouco trabalho e dispêndio, ainda que sem a devida economia, era extraído e se fundia; hoje porém não produzem aqueles restabelecimentos de ordinário um equivalente às suas despesas e trabalhos por ser muito mais raro ou por se achar entranhado pelo centro das montanhas, ou porque tendo-se recolhido quase todo que se apresentava virgem, resta talvez o que estará em diferentes estados de mineralização ou combinação para não poder ser tão facilmente conhecido por aqueles nossos mineiros que ignoram absolutamente todos os princípios fundamentais da arte de trabalhar as minas.

\section{S 2}

Para o Brasil não consta ter passado até hoje um só professor de Minas Metalúrgicas e de Docimástica, para ali dirigir e ensinar tão importantes trabalhos aos nossos mineiros. Uma prática tradicionária dirigida por um mui antigo e vicioso método ali estabelecido desde o princípio daqueles trabalhos, são as luzes, que ainda hoje servem de guia para extrair o ouro de suas diferentes matrizes, de o fundir e de o ensaiar nas reais fundições daquele continente, onde jurisconsultos nos lugares das suas intendências são os que ordenam e regulam aquele negócio por mãos tão hábeis como os daqueles nossos mineiros: donde se pode segurar que a causa primeira de não produzirem hoje as minas tanto interesse real, como nos primeiros tempos, é sem dúvida a falta dos precisos conhecimentos por seus operários e diretores. 


\section{\& 3}

Esta falta em os nossos mineiros, e sobretudo nos fundidores, diretores e inspetores de tão importantes trabalhos ocasionam indubitavelmente a perda de uma grande porção de ouro, que umas vezes por não se apresentar à vista daqueles operários, debaixo de seu brilhante metálico, outras vezes por ser intimamente dividido em particulas sutilissimas se perde ou é

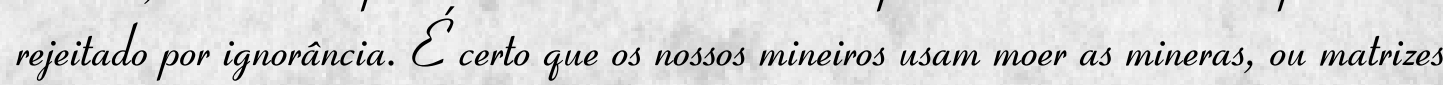
do ouro, quando observam nelas veios, ou pontos auríferos; é certo que depois usam do azougue para as amalgamar; é certo enfim que nas bateagens e lavagens das terras e areias, algumas vezes empregam cobertores, baetas para aproveitarem o ouro sutil que por seu pouco peso é levado pelas águas das lavagens. Porém nada destas operações pode convencer de um inteiro aproveitamento na sua extração, quando a experiência tem mostrado que aquelas mesmas terras que eles ali rejeitam por destituidas e expurgadas de metal, e outras, em que o ouro se acha oxidado ou diferentemente mineralizado por manipulações particulares da natureza, dão uma mui suficiente porção de ouro, sendo tratadas segundo os princípios docimásticos.

\section{S 4}

Esta perda do ouro não é o único prejuizo em as nossas minas por falta dos necessários conhecimentos de arte; ela pode muitas vezes fazer passar por ouro fino ainda mesmo naquelas fundições, e depois dos ensaios, o que na verdade não o é, pela combinação em que pode estar com algum outro metal de iguais ou semelhantes propriedades, como é a platina. Este metal, que se acha na parte da. América Cspanhola e que é possivel havê-lo também em nossas minas, tem todas as propriedades gerais do ouro, até mesmo o seu toque; sucedendo com efeito que se encontre com o ouro, e que sejam ambos levados juntamente às fundições, pode ali muito bem enganar os nossos fundidores e ensaiadores, depois de fundidos. Assim o sucedeu em 1782 em uma das casas da nossa moeda indo eu por ordem do respeitável ministério fazer certo exame sobre o ouro das minas do ouro preto, e a platina, que tendo unido em determinada proporção resultou uma massa metálica da mesma cor do ouro e quilates do mais fino; fenômeno que fez surpreender ao hábil ensaiador daquela Real Oficina. Nós possuímos variedades de ouro, quem sabe se entre estas haverá a platina, que ocasionando umas vezes 
pela maior porção dificuldades nas depurações e fusões, seja por isso desperdiçada uma quantidade de ouro; outras vezes por menos porção em combinação de um metal heterogêneo, que venha a circular como ouro puro! Uma moeda de tal qualidade de ouro não terá certamente o devido valor intrínseco e será falsa tendo contudo os mesmos quilates da boa, vindo por isso a padecer involuntariamente o comércio e o crédito da moeda nacional. 


\section{Cap. $2^{\circ}$}

\section{Que a mesma diminuifão provém também do uso da circulação do ouro em pó}

\section{s 5}

Nas minas é proibida a circulação de toda a moeda de ouro, sendo a comutação do seu comércio interior em ouro em pó. Cste uso é tão prejudicial às rendas reais, como contrário ao aumento da massa produtiva daqueles trabalhos, e à riqueza nacional; pois que desta sorte usando todo o mundo de pequenas porções deste metal para as suas domésticas precisões, não pode deixar de perder-se certa quantidade de ouro todos os dias por maior que seja o seu cuidado, ou já nas divisões de pesos mínimos, ou já nas mudanças de papelinhos bolsas. Desta perda resulta um necessário desfalque nos quintos reais, e de certa quantidade do trabalho que foi empregado na sua extração.

\section{s 6}

Este estilo de circulação ocasiona ainda outros dois notáveis prejuízos: um àquele mesmo rendimento real pelo transuio, que todos os dias se faz de ouro em pó, outro ao comércio, pela admissivel falsificação de mil maneiras praticada pela cobiça, em que, persuadindo-se o negociante de ordinário pelo saldo de suas contas possuir, por exemplo, cem marcos de ouro, se acha depois da fundição com prejuízo de cinco, e mais /c; danos que só poderia obviar a geral circulação de uma moeda positiva, junta com aquelas considerações politicas de uma prudente e econômica administração. 


\section{Cap. $3^{\circ}$}

\section{Da necessidade de regular os trabalhos das minas do ouro desde a sua extração até a redução em moeda}

\section{\& 7}

Pelo que fica expendido /c.c. 1-2\% / se colige o ponto de precisão que há de regular de baixo de vistas mais ativas, e inteligentes os estabelecimentos das minas do Brasil para que inteiramente se aproveite, e por todos os meios se economize toda a quantidade de ouro que ali tiver a natureza produzido debaixo de qualquer estado que seja, ou possa ser de mineralização, e se evitem do modo mais possivel todas as perdas e prejuizos ponderados.

\section{\& 8}

Esendo indubitável que a liberdade de semethantes trabalhos depende de um Direito Real I porque sendo a superficie do terreno a única parte de admissivel propriedade para a agricultura e outras necessidades da vida humana, e o seu interior, que não faz jamais parte daquela repartição, conservado em direito privativo do Soberano, pela geral utilidade que resulta ao bem comum/ segue-se que a direção deste objeto só ao Príncipe pertence, como supremo legislador, estabelecer por positivas disposições, que, como leis invioláveis, devem regular, facultar, e ordenar tais trabalhos a fim de evitarem-se todos quaisquer prejuizos, inconvenientes, e má fé que possam ser diametralmente opostos a seus fins politicos.

\section{9}

Os multiplicados regulamentos dos Estados da Suécia, da Alemanha e da França sobre este importante objeto de suas minas, seriam suficientes a persuadir-nos da precisão de iguais cuidados, e vistas nas minas do Brasil onde como, tenho dito, a inveterada desordem no regulamento econômico de seus trabalhos tende a uma total ruína. ¿'verdade que ali há 
intendências debaixo de cujas vistas são dirigidos os negócios das minas do ouro; porém apesar de serem, e haverem sido estes importantes lugares ocupados por sábios e zelosissimos, e bem dignos ministros, também é verdade que estas administrações respeitáveis mais tendem a formalidades judiciais, que a dirigir, examinar, reparar, e ensinar os meios de semelhantes trabalhos para serem verdadeiramente interessantes ao Cstado.

\section{s 10}

Entre os meios os mais eficazes que têm achado aqueles estados particularmente a França para tirarem todo o proveito possível de suas minas metálicas foram $1^{\circ}$ o estabelecimento de aulas públicas onde se ensinam os conhecimentos da arte de trabalhar as minas; $2^{\circ}$ a reserva nas amplas concessões de liberdade de trabalhos qualquer individuo com posse absoluta; $3^{\circ}$ finalmente o erigir conselhos superiores de politica das minas para o cuidado desta repartição dos negócios públicos. Mo estabelecimento dos estudos é digno de ler-se o estatutol de confirmação, dos decretos do Conselho de Estado de França de 12 de junho de 1778, e de 21 de março de 1781 / estabelecido pelo decreto do mesmo conselho em 19 de março de 1783, pelo qual se criaram dois professores: um para ler as lições da Mineralogia, da Química e da Docimástica, e outro para ensinar a Física, e Geometria subterrânea, a Hidráulica,o modo de fazer com a precisa economia as escavações e galerias das minas, e de renovar o ar interior, e o conhecimento e construção das máquinas e fornos necessários àqueles trabalhos. Ma reserva das concessões, foram ordenadas e declaradas as condições debaixo das quais elas seriam permitidas.

\section{s 11}

Para o estabelecimento, enfim, dos conselhos superiores dos trabalhos das minas se criaram na mesma França por outro decreto do Conselho de Estado de 1781, quatro inspetores instruidos nos conhecimentos desta arte, aos quais debaixo das ordens e comissões dimanadas da Administração Geral das Finanças, se encarrega o cuidado não só de examinar a situação, extração, regularidade, e economia das minas de sua repartição, mas ainda de vigiar sobre a segurança das vidas dos seu obreiros, ajudar com seus conselhos a seus mineiros 
ou diretores com obrigação de darem conta de suas observações e procedimentos à intendência respectiva, em um exato, e bem circunstanciado jornal de suas visitas para serem apresentadas pela mesma intendência à Suprema Administração Geral.

\section{s 12}

abuso das amplas concessões de terrenos para ser espoliado nas minas do Brasil, pede particular atenção, visto que por falta dos precisos conhecimentos umas são abandonadas por mal dirigidas, e trabalhadas, e outras porque depois de terem mostrado veios ricos, largos, e bem regulares ao princípio por se interromperem por causas naturais desanimam aos seus operários, donde resulta um notável prejuizo principalmente às últimas, nas quais alucinados logo no princípio de seus trabalhos os nossos mineiros, e não julgando necessária uma exata economia, empregam muitas vezes mais despesas e trabalhadores, vindo depois a estacaremse e a abandonarem a mina por exausta. Isto não aconteceria se as datas das permissóes só fossem conferidas a quem mostrasse ter qualidades para empreenderem tais trabalhos, e debaixo das restritas condições estipuladas, e fielmente guardadas pelos Conselhos das Intendências Reais.

\section{s 13}

Estes Conselhos da Policia das Minas do Ouro do Brasil poderiam ser as mesmas intendências compostas de certo número inspetores, sujeitos de conhecidas luzes daquele negócio, constituindo um corpo regular debaixo da presidência do seu respectivo intendente, os quais seriam encarregados de visitar cada um o seu distrito anualmente indicado, para observar as minas ali existentes, notar os seus trabalhos, remediar os seus erros, e defeitos, calcular as suas riquezas, produtos e vantagens, para de tudo ser informado exatamente o Soberano.

Nestes conselhos se deliberariam, se discutiriam, e se julgariam de comum acordo os negócios concernentes ao objeto das minas. Seria necessário igualmente que estes inspetores não fossem perturbados nos exercícios de suas funções pelo capricho daqueles mineiros, sendo antes por eles reconhecidos em qualidade de tão importante emprego, e gozar dos mesmos 
privilégios, isenções, e prerrogativas de que gozam os inspetores gerais das Manufaturas do Reino.

\section{s 14}

Todas estas providências serviriam sem dúvida a estabelecer a boa ordem e economia nos trabalhos das nossas minas, ao devido arranjamento naquela parte das finanças, porém não poderiam evitar os prejuízos ocasionados pelo uso da comutação mercantil em ouro em pó; o estabelecimento de uma moeda efetiva, e de uma casa de moeda, com a absoluta proibição do uso do ouro em pó, tudo debaixo das vistas daqueles Conselhos de Intendência da Polícia das Minas, seriam os meios mais eficazes para esse fim a meu pensar; desta sorte o direito dos quintos junto com o limitado estipulado da senhoreagem ou moedagem constituiria um rendimento avultado nas rendas reais daquela conquista.

Disse 


\section{NOTAS:}

*Este trabalho se insere nos projetos de pesquisa 'Emergência e consolidação das ciências naturais no Brasil (1770-1870)' (proc. Fapesp no. 00/04751-0) e 'Ciências naturais no Brasil na Colônia e no Império' (proc. CNPq nº 460421/00-0), coordenados pelas professoras doutoras Maria Margaret Lopes e Silvia F. de M. Figueirôa. Integra igualmente a pesquisa de doutoramento de Clarete Paranhos da Silva, que conta também com o apoio da FAPESP/Brasil (no 00/14396-3).

${ }^{1} \mathrm{O}$ italiano Domingos Vandelli (1730-1815) foi o primeiro lente de química e história natural da Universidade de Coimbra após as reformas pombalinas. Exerceu suas atividades naquela instituição entre os anos de 1772 e 1791 . Foi um dos mais vigorosos impulsionadores da criação da Academia Real das Ciências de Lisboa (1779). Vandelli transitou por alguns dos espaços de investigação mais importantes criados durante o processo reformista iniciado pelo ministro de dom José I, marquês de Pombal (1699-1782), e continuado por seus sucessores. Durante seu trabalho como professor e investigador em Coimbra, Vandelli e seus alunos utilizavam o Laboratório Químico, o Gabinete de História Natural e o Jardim Botânico. Ao mesmo tempo Vandelli participava ativamente dos trabalhos da Academia Real das Ciências de Lisboa, como diretor da classe das ciências da observação, bem como do Museu da Ajuda (Brigola, 2000). Carvalho (1987) destaca o fato de Vandelli ser o encarregado da "direção de todos os departamento de História Natural, tanto na Universidade de Coimbra como na Ajuda".

2 Ver nota 4.

${ }^{3}$ Livro de Registro da Vedoria Geral da Capitania do Ceará, fls. 9v e 10v. (apud Silva Nobre, op. cit., pp. 177-8).

${ }^{4}$ Além de seus trabalhos sobre a capitania do Ceará, Feijó deixou inúmeros outros documentos que englobam desde sua estada em Cabo Verde até sua chegada ao Brasil, nomeadamente ao Ceará. A lista a seguir completa a base documental que encontramos até o estágio atual de nossas pesquisas: Estado presente das experiências do salitre na Ribeira do Alcântara, em $1^{\circ}$ de março de 1798, Biblioteca Nacional de Lisboa, reservados, cód. 610 (F.R. 762); Memória sobre a fábrica real de anil da Ilha de Santo Antão, publicada nas Memórias econômicas da Academia Real de Ciências de Lisboa (ARCL), tomo 1, 1789, pp. 407-21; Memória sobre a urzella de Cabo Verde, publicada em Memórias econômicas da ARCL, tomo 5, 1815, pp. 145-54; Ensaio político sobre as ilhas de Cabo Verde para servir de plano à história filosófica das mesmas, publicado no Patriota, n 5, nov. de 1813; Memória sobre a última erupção vulcânica do Pico da Ilba do Fogo, sucedida em 14 de Janeiro do ano de 1785, observada e escrita, etc., publicada no Patriota, tomo 3, n 5, 1814, pp. 23-32; Ensaio econômico sobre as ilhas de Cabo Verde, provavelmente lido na Academia em 1797 (Guedes, op. cit.) e publicado pela mesma Academia em 1815; Itinerário filosófico que contém a relação das ilhas de Cabo Verde, disposta pelo método epistolar. Dirigidas ao ilustríssimo e excelentíssimo senhor Martinho de Mello e Castro, pelo naturalista régio das mesmas ilhas João da Silva Feijó, 1783, Biblioteca Nacional, manuscrito, cód. 12984; Estado presente das experiências do salitre na Ribeira do Alcântara, em $1^{\circ}$ de março de 1798. Biblioteca Nacional de Lisboa, reservados, cód. 610 (F.R. 762).

${ }^{5}$ Manuscrito no Museu Paulista, coleção José Bonifácio, D-79.

${ }^{6}$ Para um aprofundamento da discussão em torno dos debates sobre a questão da mineração no Império português no período, ver Lopes et alii (2004).

${ }^{7}$ Varela (2001) e Varela, Lopes e Fonseca (2002) estudaram as memórias de José Bonifácio de Andrada e Silva. José Vieira Couto foi estudado por Clarete Paranhos da Silva, em dissertação de mestrado defendida em 1999 no Instituto de Geociências da Unicamp e publicada em livro (Silva, 2002). Sobre este último naturalista, ver também Figueirôa e Silva (2001).

${ }^{8}$ Conforme sugere carta de Feijó para Vandelli, escrita de Lisboa em 23 de julho de 1797, mencionada também por Guedes (2000).

\section{REFERÊNCIAS BIBLIOGRÁFICAS}

Blake, A. V. A.

Sacramento

1898

Brigola, João

Carlos Pires

2000

Carreira, António 1986
Diccionario bibliográfico brazileiro, vol. 4.

Rio de Janeiro, Typographia nacional.

Coleções, gabinetes e museus em Portugal no século XVIII.

Tese de doutoramento, Universidade de Évora, Évora. (mimeo.)

'Apresentação e comentários'. Ensaio e memórias econômicas sobre as ilhas de Cabo Verde (século XVIII), por João da Silva Feijó. Lisboa,

Instituto Caboverdiano do Livro. 
Carvalho, Rômulo de 1987

Figueirôa, Silvia

Fernanda de Mendonça,

Silva, Clarete Paranhos da 2001

Guedes, Maria Estela 1997

Guedes, Maria Estela,

Arruda, Luís 2000

Lopes, Maria Margaret; et alii 2004

Nobre, Geraldo da Silva 1978

Pinheiro, Rachel, Lopes, Maria Margaret 2000

Silva, Clarete

Paranhos da 2002

Silva, Maria Beatriz

Nizza da

1999

Simom, William Joel 1983

Varela, Alex Gonçalves, Lopes, Maria Margaret, Fonseca, Maria Rachel Fróes da 2002

Varela, Alex Gonçalves 2001
A história natural em Portugal no século XVIII. Lisboa, ICALP/Ministério da Educação.

'Enlightened Mineralogists: mining knowledge in colonial Brazil, 1759-1825'. Osiris, vol. 15, pp. 175-89.

'João da Silva Feijó: viagem filosófica a Cabo Verde'. Asclépio, vol. XLIX, nº 1, pp. 131-8.

'Feijó: naturalista brasileiro em Cabo Verde - século XVIII'.

Em As ilhas e o Brasil. Portugal/Madeira, Centro de Estudos de História do Atlântico/Secretaria Regional de Turismo e Cultura, sem autor, pp. 509-23.

'Scientific culture and mineralogical scientific activities in the Luzo-brazilian Empire - João da Silva Feijó (1760-1824)'. Science in Context, (no prelo).

João da Silva Feijó: um naturalista no Ceará. Fortaleza, Instituto Histórico do Ceará/GRECEL.

João da Silva Feijó (1760-1824) no Ceará: um elo entre a ilustração luso-brasileira e a construção local das ciências. Rascunho, 6 p.

O desvendar do Grande Livro da Natureza: um estudo da obra do mineralogista José Vieira Couto, 1798-1805. São Paulo, Annablume/Fapesp/Unicamp.

A cultura luso-brasileira: da reforma da universidade à independência do Brasil. Lisboa, Editorial Estampa.

Scientific expeditions in the portuguese overseas territories (1783-1808) and the role of Lisbon in the intellectual-scientific community of the late eighteenth century. Lisboa, CEHCA./Instituto de Investigação Científica Tropical.

'Os minerais são uma fonte de conhecimento e de riquezas.

As Memórias mineralógicas produzidas por José Bonifácio de Andrade e Silva'. História, Ciências, Saúde - Manguinhos, vol. 9(2): 405-26.

'Juro-lhe pela honra de bom vassalo e bom português': filósofo natural e homem público - uma análise das memórias científicas do ilustrado José Bonifácio de Andrada e Silva (1780-1819). Dissertação de mestrado, Instituto de Geociências/ DGAE/ Unicamp, Campinas. (mimeo.) 